\section{Parametric (Geo)Design for Test Planning}

Gl_Forum 2019, Issue 1

Page: $105-118$

Full Paper

Corresponding Author:

christoph.schaller@bfh.ch

DOI: 10.1553/giscience2019_01_s105

\author{
Christoph Schaller
}

Bern University of Applied Sciences (BFH), Switzerland

\begin{abstract}
The revised Swiss Spatial Planning Act (RPG 2016) pursues the goal of inward settlement development to slow down urban sprawl and better protect arable land. This needs to be addressed in planning processes, as quality-oriented and sustainable internal densification is required. The Geodesign Framework by Steinitz is suitable for supporting such planning processes with public participation, where models and visualizations help to convey the complex systemic interrelationships to stakeholders. This paper presents a process model based on Geodesign that integrates GIS and Parametric Design, so that effects on internal densification caused by changes to building regulations can be quantified and communicated. In addition to an overview of the process model, selected results from its tests and verification are presented. The results suggest that the model approximates real interrelations well and is a suitable basis for further work.
\end{abstract}

\title{
Keywords:
}

spatial planning; geodesign; parametric design; test planning; spatial simulation

\section{Introduction}

\subsection{Motivation}

With the revised Spatial Planning Act (RPG 2016), the issue of internal densification has gained further importance in Switzerland. The revised planning objectives aim to limit the growth of settlements and focus on inward development in order to slow down urban sprawl and better protect arable land (RPG, 2016). The Confederation, cantons and municipalities must adapt their planning objectives and instruments accordingly. This calls for greater attention by planners and architects, as quality-oriented, sustainable internal densification is required (Angélil et al., 2016).

Assessment of the quality in dense settlement structures requires a holistic approach to density which takes into account not only built density but also other influencing factors (Angélil et al., 2016; Grams, 2015, pp. 11-13; Schmid, 2007). These influences need to be considered because they are closely associated with various obstacles to densification, 
obstacles which must be overcome by creating acceptance among the public and politicians in order to successfully implement inward settlement development (Bundesrat, 2017; Grams, 2015, p. 77). Since public involvement in the revision of planning instruments is crucial, a combination of informal and formal procedures with varying degrees of participation is recommended (Grams, 2015, p. 123; Van Wezemael et al., 2014).

Geodesign and in particular the framework proposed by Steinitz (2012) are a suitable basis for the design of such participative planning processes (Moura, 2015; Wissen Hayek et al., 2016). Test planning as a cooperative planning procedure also has the potential to identify possible solutions and to support the development of a common understanding through the comparison of competing ideas (Grams, 2015, p. 64; Scholl et al., 2013). Due to the limited specialist knowledge of politicians and the public alike where planning is concerned, the procedures involved require target-group-specific communication of the complex planning issues (Scholl et al., 2013; Van Wezemael et al., 2014). Models and visualizations are suitable tools whose importance increases with the complexity of the planning questions (Van Wezemael et al., 2014; Walz et al., 2008).

\subsection{Goals}

The Dencity competence area for Urban Development and Mobility at Berne University of Applied Sciences uses Parametric Design as part of test planning to communicate the effects of densification on space. Although some spatial data is used as input, its integration into the design tools used is often inadequate. The goal of this paper is to present a process model to support test planning, which is based on the Geodesign framework proposed by Steinitz (2012) and systematically integrates GIS with Parametric Design. The model was developed in a UNIGIS Master's programme and first presented in Schaller (2018). It aims to quantify and visualize different scenarios to more easily evaluate and communicate the effects on internal densification caused by modifications to abstract building regulations. The selection and integration of suitable spatial data, and a parametric model form the basis for the generation of densification variants. This model supports relevant building law parameters as well as the analysis and assessment of density in the actual situation and in variants generated by using selected indicators.

First, the process model's background and the methodology are summarized. This is followed by an overview of the model's structure and implementation. Selected results from the application on two test sites are presented. During development, these sites served as means to verify the model's transferability, and as a basis for an evaluation of the process model in an expert workshop as well as for a sensitivity analysis of the central parametric model. Finally, the results are discussed and conclusions are drawn. 


\section{Literature Review}

\subsection{Parametric Design}

Jabi (2013) defines Parametric Design as a process based on algorithmic thinking that allows the expression of parameters and rules that together define, encode and clarify the relationship between the intention and the response of a design. This process depends at its core on suitable tools and parametric models, which is why the term Parametric Modelling is also used in this context (Frazer, 2016; Janssen and Stouffs, 2015; Monedero, 2000). A parametric model implements the algorithmic thinking in the parametric design process as a concrete algorithm (Patrick Janssen in Frazer, 2016). In a review, Monedero (2000) identifies five approaches to parametric modelling, which differ primarily in the way parameters as well as constraints are defined and considered when generating geometries. Janssen and Stouffs (2015) propose a generalized model for parametric modelling based on directed acyclic graphs, and derive a taxonomy for parametric modelling approaches from it. The model's central differentiation criterion is the type of iteration that it supports Janssen and Stouffs 2015). The model and taxonomy facilitate the categorization and understanding of common methods of parametric modelling.

\subsection{Geodesign}

Geodesign can be defined as spatial planning based on scientific knowledge supported by GIS (Dangermond, 2010; Goodchild, 2010). It follows a systemic approach that links design and science by integrating data, analysis and methodologies based in science into the design process. It considers critical environmental, social and economic factors from the outset, thereby improving the quality and sustainability of the process results (Dangermond, 2010; Foster, 2016; Goodchild, 2010; Steinitz, 2012). GIS is vital for the administration, processing, analysis and visualization of the spatial data required in the process (Dangermond, 2010; Goodchild, 2010; Steinitz, 2012). In addition to work by McHarg (1969) on landscape planning, which anticipated central aspects of both Geodesign and GIS, the ideas and work of Carl Steinitz in particular have contributed to the establishment of Geodesign in its current form (Dangermond, 2010; Goodchild, 2010). This led to the development of a comprehensive framework for Geodesign (Steinitz, 2012). The framework's structure and questions show parallels to other process models for design, but it is an open framework for defining individual Geodesign processes rather than a fixed process (Foster, 2016). It includes an iterative approach and the involvement of actors from the fields of design, science and society (Steinitz, 2012).

\subsection{Spatial planning and settlement development}

The overarching objectives of Swiss spatial planning, which is coordinated between the federal levels, are the appropriate and economical use of land as well as the orderly settlement of Swiss national territory (BV, 1999). With the revision of the Spatial Planning 
Act, the planning objectives were adjusted to slow down urban sprawl and better protect arable land (RPG, 2016). Settlement growth is to be contained and settlement development to be directed inwards. This inward development must be carried out with due regard to appropriate quality of life.

In addition to built density, other factors such as social intermix, green space, transport infrastructure and townscape must be considered in assessing the quality of densified settlement structures (Angélil et al., 2016; ARE, 2007; Schmid, 2007). This is reflected in various density concepts, such as built density, regulatory density, space user density, population density and social density (Spiegel, 2000). These diverse influencing factors must also be taken into account because they are connected to various socio-cultural, legal, technical and economic obstacles to the acceptance of densification (Bundesrat, 2017). Overcoming these obstacles and creating acceptance among the public and politicians is crucial for successful inward settlement development (Bundesrat, 2017; Grams, 2015, p. 77). The results of the interdisciplinary National Research Programme (NRP) 65 New Urban Quality (NFP65, 2017) provide pointers for the implementation of quality-oriented settlement development. The programme included projects on the fundamentals for determining sustainable settlement development patterns (Wissen Hayek et al., 2013), for the analysis of urban potentials and the development of strategies in metropolitan territories (Angélil et al., 2016), and for the design of municipal development processes and political planning strategies (Van Wezemael et al., 2014).

For sustainable planning and implementation of internal densification, locally adapted approaches and strategies involving the population affected are necessary (Grams, 2015; Van Wezemael et al., 2014; Wissen Hayek et al., 2013). Test planning as a cooperative planning procedure can contribute to the formation of a common understanding, to answering questions, and to communicating the need for densification, by weighing up different test drafts in a dialogue between the client, planners and public (Grams, 2015, p. 64; Scholl et al., 2013). Target-group-oriented communication is important in such planning processes due to the limited expertise in planning among politicians and the public (Scholl et al., 2013; Van Wezemael et al., 2014). Models and visualizations are valuable tools whose importance as a basis for decision-making increases with the complexity of the planning issues (Van Wezemael et al., 2014; Walz et al., 2008). Regarding densification, three-dimensional representations and parametric models especially can help to illustrate the existing structures of the built environment, reserves for potential internal densification, and the effects of modifications to building law as well as the resulting densification of space (Beirão et al., 2012; Grams, 2015, 150; Neuenschwander et al., 2014).

\subsection{Parametric Design and Geodesign in spatial planning and settlement development}

In architecture and planning, the potential for the application of Parametric Design and Parametric Modelling exists (especially in projects that aim to find solutions to complex 
problems) that takes into account influences from society and the environment (Frazer, 2016; Mehaffy, 2011). Parametrically prepared zone plans to convey the effects of planning processes (Moura, 2015; Wissen Hayek et al., 2014), integration of green spaces in settlement structures (Neuenschwander et al., 2014), and designs and analyses of entire cities (Beirão et al., 2012; de Monchaux, 2010) are all examples from the field of spatial planning with just such potential for the application of Parametric Design and Parametric Modelling. When using parametric models in the context of Geodesign processes, inputs from GIS and other models ensure that design decisions are based on verified information and in consideration of the spatial context, thus avoiding results that are guided purely by aesthetic considerations (Beirão et al., 2012; Goodchild, 2010; Mehaffy, 2011). In general, the systemic approach and the integration of methods from different disciplines ensure the necessary comprehensiveness and sustainability within the process (Dangermond, 2010). Applications of Geodesign in the context of spatial and utilization planning show that Steinitz's Framework is a suitable basis for planning processes in these areas, especially because of its openness and the emphasis on participation by the public affected (Moura, 2015; Wissen Hayek et al., 2016).

\section{Methodology}

\subsection{Development and verification}

The process model was developed using a test site in the municipality of Langenthal, which had already been the subject of a densification study by Dencity (Gilgen, 2016). After the first version of the model had been completed, the model was applied to a second, larger site in the municipality of Wohlen bei Bern, to demonstrate its transferability. Both sites have similar peri-urban characters, although the Langenthal site leans more to the urban and the Wohlen site more to the rural side. Selected scenarios for the two test sites were defined as the basis for an expert assessment. They served as input for a workshop with architects and spatial planners from Dencity. Finally, a large number of densification variants were generated for the two test sites as the basis for a sensitivity analysis of the parametric model. For this purpose, all permutations within a predefined set of parameters and value ranges were systematically generated. The resulting densification variants were analysed for correlations between the parameters investigated and selected density ratios.

\subsection{Data and software used}

Pre-existing spatial and statistical data was used as the basis for the process model, including data from the official cadastral survey (e.g. parcels and land cover), harmonized data on building zones from the Federal Office for Spatial Planning, GEOSTAT data from the Federal Statistical Office, swissBUILDINGS 3D 2.0 data from swisstopo with 3D models of the actual buildings, as well as data from other sources. Where possible, freely available data was preferred over chargeable data sources. The transferability of the model was ensured by 
using data that is available throughout Switzerland in the same or at least in a similar form thanks to standardized data models.

With the exception of CAD software Rhino 5 with its Grasshopper extension for parametric modelling, this work used open-source software. The central parametric model programmed in Grasshopper was inspired by similar models employed by Dencity. However, the parametric model pursues different approaches, especially when it comes to the integration of GIS, the derivation of building footprints by Quadtree decomposition, and the generation of steep roofs using approximated Medial Axis Transforms. Throughout the process, data is stored and analysed using the relational database management system PostgreSQL 9.1 with the PostGIS 2.1 extension for handling spatial data. QGIS 3 serves to edit, analyse and visualize spatial data. The $\mathrm{R}$ statistical package is used to perform additional analyses and to generate visualizations. The Python scripting language serves to automate and integrate different parts of the parametric model, including the implementation of interfaces for spatial data integration using GeoJSON as the interface format, the export of R-based calculations as graphics, as well as generating QGIS project files for the creation of reports.

\section{Process model to support planning of urban densification}

\subsection{Overview}

The process described by Steinitz (2012) for the elaboration of Geodesign processes was applied to develop the process model shown in Figure 1. The framework served to structure not only the work, but also the process model itself. The result is a version of the Geodesign Framework tailored to the question of internal densification. It is intended to be used for test planning within informal planning procedures. The process model is designed as an integrated model for internal densification, with a coordinated process, data model and technical support. The model is divided into two phases to understand the current situation, and to define densification scenarios as well as to analyse them. Both phases are divided into three steps each. These steps are linked to specific sub-models, which treat aspects of the overall model. Figure 1 shows these steps on the left, while the technical implementation is indicated in the middle, and the associated activities are listed on the right. 

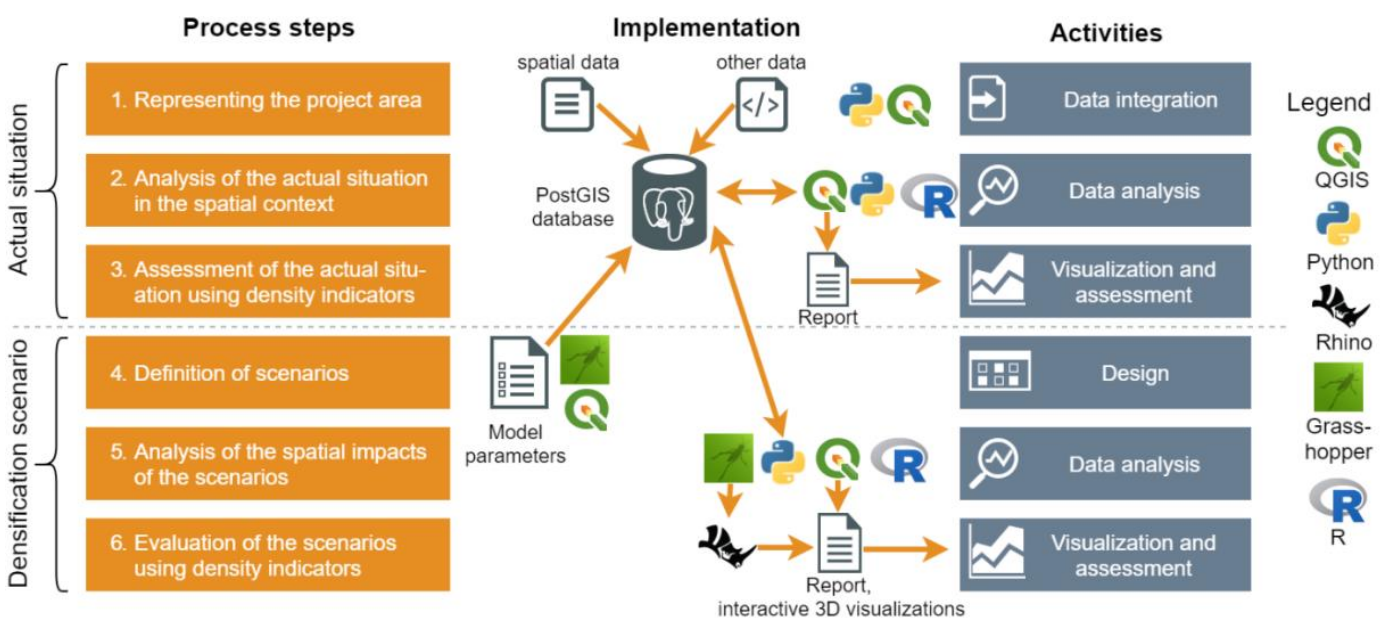

Figure 1: Overview of the process model for supporting test planning of internal densification

\subsection{Analysis of the actual situation}

The first phase of the process aims at understanding and evaluating the current situation in the project area. The first step maps the project area within the Representation Model. For this purpose, a spatial database that includes various data from different sources was established. The resulting central PostGIS database, which combines all data required for the process model, serves as input for the analyses and application of the parametric model in the subsequent steps.

In the second step, an analysis of the actual situation is carried out with the Process Model to create an understanding of the density and the (spatial) interconnections in the project area. To this end, selected key figures provide a comprehensive view of density from different perspectives. A group of indicators analyse the structure of the current building based on typology, building height, number of storeys and floor area. These factors not only influence the perception of the space and its quality in terms of architecture and design, but also indirectly influence the achievable density (Angélil et al., 2016; Grams, 2015). A second group of indicators quantify built density expressed in terms of floor area, building volume, built-up area, as well as ratio of open space. This ratio also contributes to the quality of density, since the appropriation as well as the use of open spaces are part of (urban) quality and contribute to social density through interactions between people (Angélil et al., 2016; Spiegel, 2000). Aspects of social density are addressed by a third group of indicators, which include statistics such as space user density, employee density, population density, housing density, household density, and the average living space per inhabitant. Additional contextual information, such as the planning zones and access to public transport, supplements the indicators. Most of the key figures are prepared directly in the central database, while some statistical evaluations are carried out in R. 
In the third step, the results of the analysis serve as the basis for the evaluation, within the Evaluation Model, of the actual situation by decision-makers. This step of the Geodesign process was mostly left open in Schaller (2018), as it must be adapted to the individual process and requires the participation of the decision-makers concerned. Subsequently, however, to support the evaluation visualizations were developed using R and QGIS, which prepare the analysis results and key figures in the form of interactive maps and reports for decision support.

\subsection{Definition and analysis of densification scenarios}

The aim of the process model's second phase is to explore and communicate the effects of internal densification in the project area. The parametric model for generating densification variants, which implements the Change Model in the fourth step, is central to this goal. By defining scenarios with differing parameter values, the parametric model can be used to generate new densification variants with little effort. The input parameters are based on the Intercantonal Agreement on the Harmonization of Building Terms (IVHB, 2005), which facilitates the transferability of the model to different parts of Switzerland. The parameters selected include minor and major boundary setbacks, maximum number of storeys, storey height, maximum building height, the type of usage, and the associated usage ratio. In addition to these parameters, the model uses spatial data for parcel geometries and distance lines as input to generate and visualize densification variants. An elevation model, 3D models of the actual buildings, and road surfaces are used as additional spatial inputs for the visualization. The central database serves as a source for the input data and for storing scenarios and variants generated by the model. Due to the integration of the various parts of the process model's technical implementation, the parametric model plays a central and coordinating role in the process model.

In the fifth step, the densification variants generated are analysed for their effects on the project area using the Impact Model. In addition to 3D visualizations, a subset of the key figures of the Process Model in step two is used. This allows a comparison between the variants and the actual situation. The focus lies on structural density indicators, supplemented by indicators for space user density, employment density and population density, and living space per inhabitant.

In the sixth and final step, the Decision Model aims at the evaluation and selection of variants, which will serve as a basis for further work. Like step three, the involvement of decision makers and the choice of specific variants in step six was left open (Schaller 2018), as it is necessary to adjust it to the concrete planning process. Again, analysis results are processed into decision support documents. Their structure is based on the reports and visualizations used to evaluate the actual situation, which facilitates a direct comparison. 


\section{Results}

Figure 2 illustrates the use of the parametric model on the Langenthal site using selected outputs and visualizations from one of the scenarios used for the expert review. In an iterative application, the model outputs provided indications for how to fine-tune scenario parameters for the review. In addition, these applications provided inputs for the selection of parameters and value ranges used for the sensitivity analysis. Compared to the use of various tools and plugins in previous models, the handling of spatial data in Grasshopper proved simpler, since only a single interface with the central PostGIS database needs to be supported. The Python-based interfaces and component integrations proved to be a reliable and flexible solution. The upfront data integration into the central database using GIS tools also contributed to the simplification. The time needed for the application of the process model to the second test site in Wohlen was significantly reduced, because data structures and the parametric model could be reused without modification. As the basis for the expert review, five scenarios for the Langenthal site and four for the site in Wohlen were generated. For both sites, the generation of the first scenario took the longest time because the necessary input data for the Representation Model first had to be integrated into the database. Subsequent scenarios were generated faster, since the input data could be reused and only the parametrization had to be newly created. The model's efficiency was additionally underlined by the generation of the 4,320 variants that served as input for the sensitivity analysis. By applying minor additional scripting to the parametric model, the variants could be automatically generated within a few hours. These were stored in the database, which served as data source for the subsequent statistical analysis. 

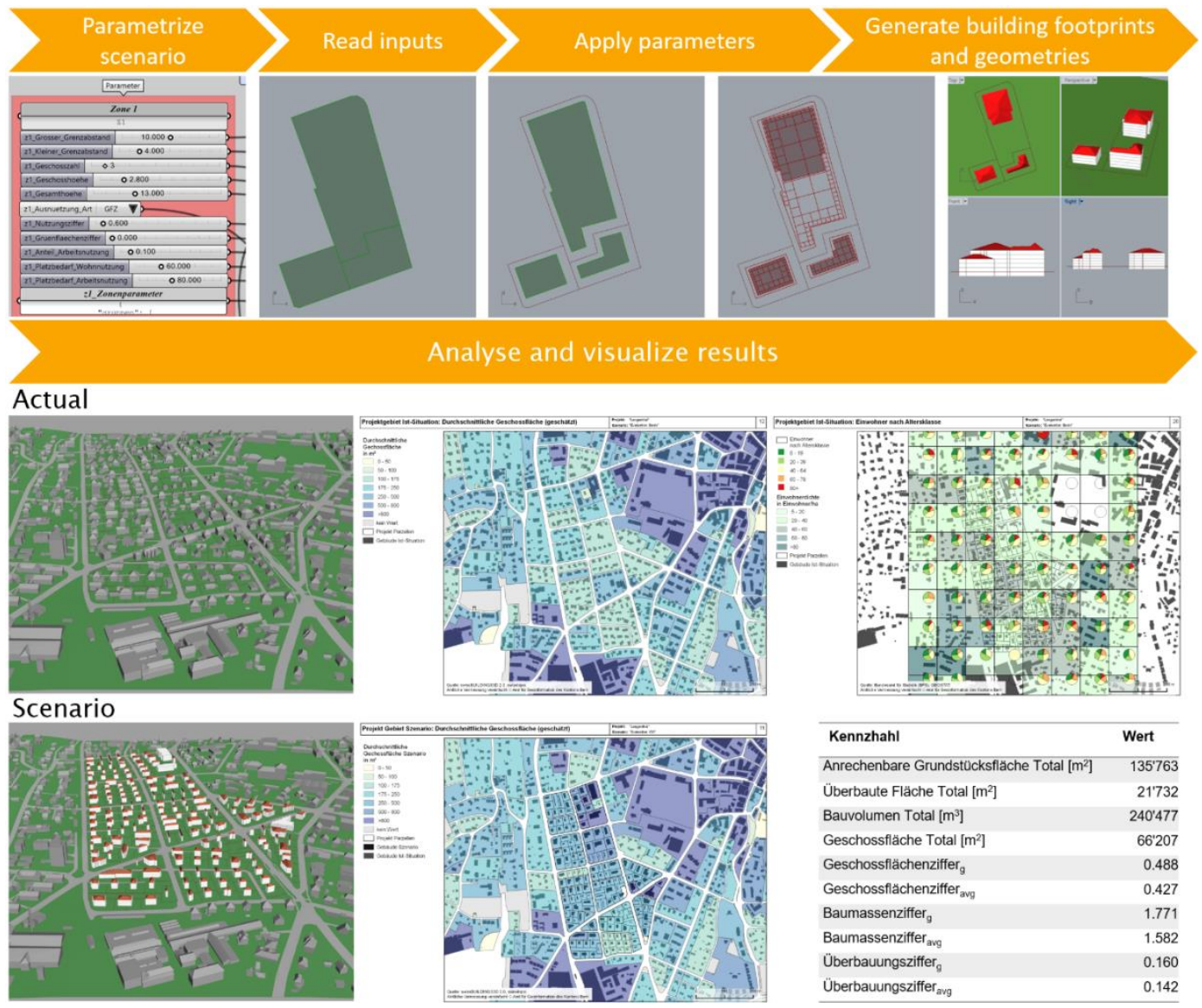

\begin{tabular}{|c|c|}
\hline Kennzhahl & Wert \\
\hline Anrechenbare Grundstucksflăche Total $\left[\mathrm{m}^{2}\right]$ & 135763 \\
\hline Überbaute Fläche Total $\left[\mathrm{m}^{2}\right]$ & $21^{\prime} 732$ \\
\hline Bauvolumen Total $\left[\mathrm{m}^{3}\right]$ & $240^{\prime} 477$ \\
\hline Geschossfläche Total $\left[\mathrm{m}^{2}\right]$ & $666^{\prime} 207$ \\
\hline Geschossflächenziffer $_{g}$ & 0.488 \\
\hline Geschossflächenziffer $_{\text {avg }}$ & 0.427 \\
\hline Baumassenziffer $_{g}$ & 1.771 \\
\hline Baumassenziffer ${ }_{\text {avg }}$ & 1.582 \\
\hline Überbauungsziffer ${ }_{g}$ & 0.160 \\
\hline Überbauungsziffer ${ }_{\text {avg }}$ & 0.142 \\
\hline
\end{tabular}

Figure 2: Illustration of the model application and selected outputs

Based on the sensitivity analysis of the model, Table 1 summarizes the observed influences of input parameters on density ratios in terms of the strength and direction of the influence. The tendencies were in line with expectations based on the analysis of the scenarios for the expert review. In the expert workshop, these results and tendencies were judged to be comparable with those of previous models. Furthermore, the experts evaluated as good the approximation of actual interrelations between building laws and density indicators. However, due to some weak points in the parametric model, the results showed lower than expected densities under certain conditions. The lack of consideration of floor areas in the roof storey and the too-generous application of the major border setbacks were identified as reasons. On narrow, elongated plots, those setbacks also lead to unrealistic building shapes that should be avoided. 
Schaller

Table 1: Influence of parameters on building density indicators

\begin{tabular}{|c|c|c|c|c|c|c|}
\hline Parameter & $\begin{array}{l}\text { gross } \\
\text { floor } \\
\text { area } \\
\text { ratio }\end{array}$ & $\begin{array}{l}\text { cubic } \\
\text { content } \\
\text { ratio }\end{array}$ & $\begin{array}{l}\text { building } \\
\text { coverage } \\
\text { ratio }\end{array}$ & \multirow{3}{*}{$\begin{array}{l}\text { Influ- } \\
\text { ence }\end{array}$} & \multirow{3}{*}{$\begin{array}{l}\text { same } \\
\text { direction }\end{array}$} & \multirow{3}{*}{$\begin{array}{l}\text { opposite } \\
\text { direction }\end{array}$} \\
\hline Usage ratio & ++ & ++ & ++ & & & \\
\hline Minor border setback & -- & -- & -- & & & \\
\hline Major border setback & -- & -- & -- & strong & ++ & -- \\
\hline Greenspace ratio & - & - & - & weak & + & - \\
\hline Number of storeys & ++ & ++ & - & & & \\
\hline Grouping of parcels & + & + & + & & & \\
\hline
\end{tabular}

The evaluation of the process model and of the underlying Geodesign approach in the expert workshop was predominantly positive. The participative aspects, the holistic approach to density, and the parametric model in particular were highlighted. Regarding the parametric model, the more realistic representation using approximated steep roofs and the derivation of the building footprints were regarded as improvements over previous models. In addition, the potential for broad applicability was attested thanks to the use of the IVHB as a guideline. Where weaknesses in the model were concerned, the need to carry out tests in real-world projects and close coordination with existing procedures were noted. Not restricting the creation of buildings to the extent of building zones in the scenarios presented was regarded as critical, since this could result in the creation of buildings outside the actual permitted zones. Furthermore, the additional consideration of minimal setbacks from roads was deemed necessary for practical use.

\section{Discussion and conclusions}

In this work, a process model to support test planning in the context of internal densification was developed. It is based on Steinitz's Geodesign Framework (2012) and systematically integrates GIS with Parametric Design. Within the process model, various outputs are generated based on spatial data and a central parametric model, which support the quantification and communication of the effects on internal densification caused by modifications to abstract building regulations. The use of data that are uniformly available (or at least available in a similar form) throughout Switzerland as well as of the IVHB as reference for the parametric model favour its transferability. This was demonstrated by the application to two different test sites. The combination of a database for central data storage and Python for interface programming enabled an efficient integration between GIS, parametric design tools and further components.

In line with previous work (Moura, 2015; Wissen Hayek et al., 2016), Steinitz's framework proved to be a suitable basis for planning processes and for the process model. The 
application of the process model to the test sites covered large parts of a typical Geodesign process. However, the lack of a concrete planning project and public participation means that the process was not complete. Nevertheless, the experiences and results from the application of the process model, the expert assessment as well the sensitivity analysis of the parametric model suggest that the model is a suitable basis for individualized Geodesign processes in test planning. With its systemic approach, together with the selection of suitable basic data and indicators, the model provides a holistic view of densification. Along with the participative aspects and the parametric model, these points were emphasized positively in an expert workshop. The parametric model, which falls into the category Procedural Modelling according to the taxonomy of Janssen and Stouffs (2015), was judged to be an improvement over previous models. The expert feedback on selected scenarios and the sensitivity analysis of the parametric model suggest that its outputs are at least comparable to those of earlier models, and that it approximates real interrelations between building laws and density indicators reasonably well. However, the results have shown some weaknesses, which will have to be addressed before the process model can be used in practice.

In conclusion, approaches like the process model presented here have great potential regarding planning processes for internal densification. The underlying systemic Geodesign approach encourages and ensures the holistic approach to density needed to overcome the diverse obstacles to densification. Parallels between the Geodesign framework and established planning standards offer starting points for integration with existing planning processes and procedures. Furthermore, the integration of GIS and Parametric Design may help to implement test planning processes more efficiently.

\section{Literature}

Angélil, M., Bornhauser, R., Christiaanse, K., et al. (2016). Urbane Qualitäten: Ein Handbuch am Beispiel der Metropolitanregion Zürich (1st ed.). Zürich, Switzerland: Edition Hochparterre.

ARE. (2007). Nachhaltige Raumentwicklung Schweiz - Kriteriensystem. Retrieved from https://www.are.admin.ch/dam/are/de/dokumente/raumplanung/dokumente/faktenblatt/nach haltige_raumentwicklungkriteriensystem.pdf.download.pdf

Beirão, J., Arrobas, P., \& Duarte, J. (2012). Parametric Urban Design: Joining morphology and urban indicators in a single interactive model. In Achten, H., Pavlicek, J., Hulin, J., Matejovska, D. (Eds.), Digital Physicality - Proceedings of the 30th eCAADe Conference - Volume 1 (pp.167-175). Prague, Czech Republic.

Bundesrat. (2017). Verdichtetes Bauen in Ortszentren fördern, aber wie? Retrieved 04.05.2019, from https://www.are.admin.ch/dam/are/de/dokumente/recht/publikationen/verdichtetes-bauen-inortszentren-foerdern-aber-wie.PDF.download.PDF

BV. (1999). Bundesverfassung der Schweizerischen Eidgenossenschaft. Bern, Switzerland: Die Bundesversammlung der Schweizerischen Eidgenossenschaft

Dangermond, J. (2010). Geodesign and GIS-designing our futures. Peer Reviewed Proceedings of Digital Landscape Architecture, Anhalt University of Applied Science, Germany.

de Monchaux, N. (2010). Local Code: Real Estates. Architectural Design, 80(3), 88-93. 
Foster, K. (2016). Geodesign parsed: Placing it within the rubric of recognized design theories. Landscape and Urban Planning, 156, 92-100.

Frazer, J. (2016). Parametric Computation: History and Future. Architectural Design, 86(2), 18-23.

Gilgen, S. (2016). Fallstudie Langenthal. MODULØR, 54-55.

Goodchild, M. F. (2010). Towards Geodesign: Repurposing Cartography and GIS? Cartographic Perspective, 66(1), 7-22.

Grams, A. (2015). Spielräume für Dichte - Problemorientierter Verfabrensansatz für Verdichtung als Element der Innenentwicklung dargestellt am Beispiel kleiner und mittlerer Gemeinden im Schweizer Mittelland. (Doctoral Thesis), ETH-Zürich, Zürich.

IVHB. (2005). Interkantonale Vereinbarung über die Harmonisierung der Baubegriffe (IVHB). Bern, Schweiz: Interkantonales Organ Harmonisierung Baubegriffe.

Jabi, W. (2013). Parametric Design for Architecture. London, United Kingdom: Laurence King Publishing. Janssen, P., \& Stouffs, R. (2015). Types of parametric modelling. Paper presented at the Int. Conf. Computer-Aided Architectural Design Research in Asia (CAADRIA 2015), Daegu, South Korea.

McHarg, I. L. (1969). Design with Nature. Garden City, USA: Published for the American Museum of Natural History [by] the Natural History Press.

Mehaffy, M. W. (2011). A city is not a rhinoceros: On the aims and opportunities of morphogenetic urban design. Built Environment, 37(4), 479-496.

Monedero, J. (2000). Parametric design: a review and some experiences. Automation in Construction, 9(4), 369-377.

Moura, A. C. M. (2015). Geodesign in Parametric Modeling of urban landscape. Cartography and Geographic Information Science, 42(4), 323-332.

Neuenschwander, N., Wissen Hayek, U., \& Grêt-Regamey, A. (2014). Integrating an urban green space typology into procedural 3D visualization for collaborative planning. Computers, Environment and Urban Systems, 48, 99-110.

NFP65. (2017). Homepage Nationales Forschungsprogramm NFP 65 Neue Urbane Qualität. Retrieved 29.03.2017, from http://www.nfp65.ch

RPG. (2016). Bundesgesetz über die Raumplanung. Bern: Die Bundesversammlung der Schweizerischen Eidgenossenschaft.

Schaller, C. (2018). Parametrisches (Geo)Design für Testplanungen - Vorgehensmodell zur Unterstützung von Planungen zur inneren Verdichtung. (Master's dissertation, Paris LodronUniversität Salzburg, Salzburg)

Schmid, C. (2007). Die Wiederentdeckung des Städtischen in der Schweiz. In V. M. Lampugnani, T. Keller, \& B. Buser (Eds.), Städtische Dichte (pp. 31-38). Zürich, Switzerland: NZZ Libro Buchverlag der Neuen Zürcher Zeitung.

Scholl, B., Vinzens, M., \& Staub, B. (2013). Testplanung - Methode mit Zukunft. Solothurn, Switzerland: Kanton Solothurn

Spiegel, E. (2000). Dichte. In H. H. Häussermann (Ed.), Grossstadt - Soziologische Stichworte, Wiesbaden, Germany: VS Verlag für Sozialwissenschaften.

Steinitz, C. (2012). A Framework for Geodesign: Changing Geograpby by Design. Redlands, USA: Esri Press.

Van Wezemael, J., Strebel, I., Schmidt, M., et al. (2014). Prozess Städtebau - Strukturen, Dynamiken und Steuerungsmodi der Raumbildung in der Gegenwart - Schlussbericht zum Forschungsprojekt 'Urbane Brüche / lokale Interventionen' im Rabmen des NFP65 'Neue Urbane Qualität'. Schweiz, Zürich.

Walz, A., Gloor, C., Bebi, P., et al. (2008). Virtuelle Welten - reale Entscheide? Die Alpen im Modellbaukasten: thematische Synthese zum Forschungsschwerpunkt $V$ «Virtuelle Repräsentation» des 
Nationalen Forschungsprogramms NFP 48 «Landschaften und Lebensräume der Alpen». Zürich, Switzerland: vdf Hochschulverlag.

Wissen Hayek, U., Eisinger, A., von Wirth, T., et al. (2013). Sustainable Urban Patterns / Nachbaltige urbane Muster Wissenschaftlicher Schlussbericht Nationales Forschungsprogramm NFP 65 «Neue Urbane Qualität». Zürich, Switzerland.

Wissen Hayek, U., Neuenschwander, N., von Wirth, T., et al. (2014). Combining Three Modelling and Visualization Tools for Collaborative Planning of Urban Transformation. Paper presented at the Digital Landscape Architecture 2014 - Landscape Architecture and Planning, Zürich, Switzerland.

Wissen Hayek, U., von Wirth, T., Neuenschwander, N., et al. (2016). Organizing and facilitating Geodesign processes: Integrating tools into collaborative design processes for urban transformation. Landscape and Urban Planning, 156, 59-70. 